\title{
Ketones from Carbon Dioxide and Organolithium or Grignard Reagents
}

$$
\begin{aligned}
& \underset{\mathrm{O}}{\|} \underset{\mathrm{O}}{\mathrm{O}} \frac{\mathrm{R}^{1} \mathrm{Li}(0.4-1 \text { equiv) }}{\mathrm{R}^{2} \mathrm{MgBr} \text { (1 equiv) }} \mathrm{R}^{1-2} \mathrm{CO}_{2} \mathrm{Li} \frac{\mathrm{R}^{3} \mathrm{Li}(2 \text { equiv) }}{-\mathrm{CO}_{2}} \\
& \mathrm{R}^{1-2}=\text { Alk, HetAr }
\end{aligned}
$$

\section{Category}

Metal-Mediated

Synthesis

Key words

carbon dioxide

organolithium

reagent

Grignard reagent

SYNFACTnere

Selected examples:

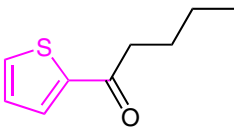

$77 \%$ yield

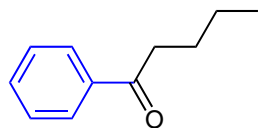

$79 \%$ yield

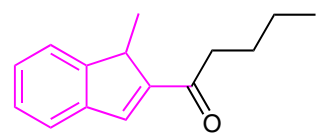

$71 \%$ yield<smiles>CCCCC(=O)c1ccccn1</smiles>

$55 \%$ yield<smiles>CCCCC(=O)c1ccc2ccccc2n1</smiles>

$40 \%$ yield<smiles>O=C(c1ccccc1)c1ccc(Cl)cc1</smiles>

$73 \%$ yield<smiles>O=C(c1ccc(C(F)(F)F)cc1)C1CC1</smiles>

$71 \%$ yield

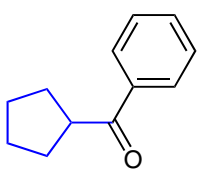

$65 \%$ yield
Significance: The authors report two complementary continuous flow systems using either stoichiometric amounts or an excess of $\mathrm{CO}_{2}$ for the preparation of ketones. Starting from organolithium or Grignard reagents, the described synthesis shows significant advantages over conventional batch conditions in suppressing undesired symmetric ketone and tertiary alcohol byproducts.
Comment: The observation that in this reaction organolithium reagents are more reactive in $\mathrm{Et}_{2} \mathrm{O}$ than in THF is unprecedented. Furthermore, by integrating an in-line generation of organolithium or organomagnesium species, a telescoped oneflow process capable of preparing ketones in a modular fashion from simple precursors has been established. 